\title{
Cre-ating ways to serotonin
}

\section{William Wisden*}

Division of Cell and Molecular Biology, Blackett Laboratory, Imperial College, London, UK

*Correspondence: w.wisden@imperial.ac.uk

\section{A commentary on}

Inducible gene manipulations in serotonergic neurons.

By Tillmann Weber, Gerald Böhm, Elke Hermann, Günther Schütz, Kai Schönig, and Dusan Bartsch (2009). Front Mol. Neurosci. 2, 24 .

Almost 50 years ago Dahlström and Fuxe discovered serotonergic neurons in the brainstem. Much remains to learn, however, about how serotonin (5-hydroxytryptamine or 5HT) modulates circuit activity. Serotonergic neurons release 5HT throughout the CNS. Accordingly, these cells influence breathing rhythms, body temperature, heart rate, pain, eating, sleep, arousal, emotion, and cognition to list a few (Hensler, 2006). When the 5HT system gets disturbed much can go wrong: sudden infant death syndrome, obesity, psychosis, depression, and anxiety (Audero et al., 2008; Garfield and Heisler, 2009; Richardson-Jones et al., 2010). Understanding these pathologies and illnesses might require, in part, new ways of manipulating serotonergic cells without affecting other cell types, as addressed by the recent study from Weber et al. (2009).

Studying circuitry with genetics often involves putting foreign proteins, e.g. Cre (cyclization recombination) site-specific DNA recombinase from bacteriophage $\mathrm{P} 1$, in specific cell types (Sauer, 2002; Dymecki and Kim, 2007; Gong et al., 2007). The regulatory regions of genes expressed only in 5HT neurons can be hijacked to put Cre in these cells (Scott et al., 2005; Weber et al., 2009). For a cell type-selective manipulation, a "Cre driver mouse" is mated with another that has a gene with recognition sites for Cre. These sites, termed lox (locus of crossover) sites, surround an important exon, and the target gene is designated a "floxed" allele. In the nuclei of those cells that express the Cre enzyme, the Cre cuts and rejoins the DNA between the lox sites, so that the intervening segment gets inverted or removed (Sauer, 2002; Dymecki and Kim, 2007l). This makes a cell type-specific knockout of a gene. A difficulty, though, is brain development. 5HT released during development influences how circuitries which govern adult behavior work (Gross et al., 2002; Ansorge et al., 2004). Knocking out the 5HT1A receptor gene in young or old mice gives different phenotypes (Gross et al., 2002); knockout during embryogenesis produces heightened anxiety in adults; but knockout in adults does not (Gross et al., 2002). Thus if we express Cre from a serotonergic-specific gene active during embryogenesis or postnatal brain development, Cre would turn on at an earlier point and by destroying a floxed gene, leave an irreversible genetic "footprint". This may prevent a correct interpretation of the adult phenotype. Inducible Cre activity, where we can turn on the Cre recombinase at defined ages of the mouse, is better. Hence the Weber et al. (2009) paper.

Weber et al. have performed a model exercise in advanced transgenesis. For directing Cre expression specifically to serotonergic neurons, they took the regulatory regions of the tryptophan hydroxylase 2 (Tph2) gene, which encodes the first enzyme of the 5HT synthetic pathway (Weber et al., 2009). A bacteriophage P1-derived artificial chromosome (PAC), a large (177 kb) piece of mouse genomic DNA that contains sufficient regulatory regions of the $t p h 2$ gene, served as the expression platform. In the PAC, the tph2 coding region was changed to produce an inducible Cre recombinase instead of the Tph2. This modified PAC was injected into nuclei of mouse embryos where it integrated randomly in the genome.

So that the Cre could be activated at specific times, the authors used Cre recombinase fused with the ligand binding region of the estrogen receptor (ER). The ER domain stopped Cre from cutting DNA. However, Cre's activity within the

${ }^{1}$ see http://cre.jax.org/introduction.html

${ }^{2} \mathrm{http}: / /$ www.gensat.org/cre.jsp
Cre-ER protein (known as Cre-ER ${ }^{\mathrm{T} 2}$ ) could be released by the drug tamoxifen, which binds to the ER segment (Indra et al., 1999). The experimental mice were generated by crossing a strain with a floxed-allele (various floxed "reporter" alleles were used by Weber et al., as examples) with the TPH2CreERT2 mice. Because Cre was inactive, the progeny were normal. At the chosen time, tamoxifen was given intraperitoneally. Some days later, Cre recombined the target gene specifically in the 5HT neurons (Weber et al., 2009).

Weber et al's study beautifully illustrates the use of inducible recombination, and the amount of work needed to fully characterize the mice (Weber et al., 2009). For this study the authors made their own mice; but many "off the shelf" Cre mouse lines are available (Gong et al., 2007), and more appear regularly (see, for example, the wonderful resource at GENSAT $^{2}$ ). Ironically the GENSAT webpage now lists a tamoxifen-inducible Cre line selective for 5HT neurons (using the Slc6a4 gene). One needs to appreciate, however, that in any of the non-inducible lines Cre can express during development, and sometimes in different cell types from the adult. For this reason some non-inducible Cre lines are not useable. Each must be assessed to see when the Cre gene turns on. In conclusion, many neurological and psychiatric diseases may come from $5 \mathrm{HT}$ malfunctions in development which then change the adult brain. The TPH2-CreERT2 mice made by Weber et al. (2009), and other inducible Cre mice, will allow investigations of when and how the diseases might first start, or what maintains them.

\section{REFERENCES}

Ansorge, M.S., Zhou, M., Lira, A., Hen, R., and Gingrich, J. A. (2004). Early-life blockade of the 5-HT transporter alters emotional behaviour in adult mice. Science 306, 879-884.

Audero, E., Coppi, E., Mlinar, B., Rossetti, T., Caprioli, A., Banchaabouchi, M. A., Corradetti, R., and Gross, C. (2008). Sporadic autonomic dysregulation and death associated with excessive serotonin autoinhibition. Science 321, 130-133.

Dymecki, S. M., and Kim, J. C. (2007). Molecular neuroanatomy's “Three Gs”: A primer. Neuron 54, 17-34. 
Garfield, A. S., and Heisler, L. K. (2009). Pharmacological targeting of the serotonergic system for the treatment of obesity. J. Physiol. 587, 49-60.

Gong, S., Doughty, M., Harbaugh, C. R., Cummins, A., Hatten, M. E., Heintz, N., and Gerfen, C. R. (2007). Targeting Cre recombinase to specific neuron populations with bacterial artificial chromosome constructs. J. Neurosci. 27, 9817-9823.

Gross, C., Zhuang, X., Stark, K., Ramboz, S., Oosting, R., Kirby, L., Santarelli, L., Beck, S., and Hen, R. (2002). Serotonin1A receptor acts during development to establish normal anxiety-like behaviour in the adult. Nature 416, 396-400.

Hensler,J.G. (2006). “Serotonin,” in Basic Neurochemistry: Molecular, Cellular and Medical Aspects, 7th Edn. eds G. J. Siegel, R. W. Albers, S. T. Brady, and D. L. Price (New York: Elsevier Academic Press), 227-248.
Indra, A. K., Warot, X., Brocard, J., Bornert, J. M., Xiao, J. H., Chambon, P., and Metzger, D. (1999). Temporallycontrolled site-specific mutagenesis in the basal layer of the epidermis: Comparison of the recombinase activity of the tamoxifen-inducible Cre-ER(T) and Cre-ER(T2) recombinases. Nucleic Acids Res. 27, 4324-4327.

Richardson-Jones, J. W., Craige, C. P., Guiard, B. P., Stephen, A., Metzger, K. L., Kung, H. F., Gardier, A. M., Dranovsky, A., David, D. J., Beck, S. G., Hen, R., and Leonardo, E. D. (2010). 5-HT1A autoreceptor levels determine vulnerability to stress and response to antidepressants. Neuron $65,40-52$.

Sauer, B. (2002). Cre/lox: One more step in the taming of the genome. Endocrine 19, 221-227.

Scott, M. M., Wylie, C. J., Lerch, J. K., Murphy, R., Lobur, K., Herlitze, S., Jiang, W., Conlon, R. A., Strowbridge,
B.W., and Deneris, E. S. (2005). A genetic approach to access serotonin neurons for in vivo and in vitro studies. Proc. Natl. Acad. Sci. U.S.A. 102, 16472-16477.

Weber, T., Böhm, G., Hermann, E., Schütz, G., Schönig, K., and Bartsch, D. (2009). Inducible gene manipulations in serotonergic neurons. Front. Mol. Neurosci. 2:24.

Received: 13 August 2010; accepted: 27 August 2010; published online: 08 December 2010.

Citation: Wisden W (2010) Creating ways to serotonin. Front. Neurosci. 4:167. doi: 10.3389/fnins.2010.00167 Copyright (c) 2010 Wisden. This is an open-access article subject to an exclusive license agreement between the authors and the Frontiers Research Foundation, which permits unrestricted use, distribution, and reproduction in any medium, provided the original authors and source are credited. 